\title{
Development and Analysis of the Magnetic Circuit on Double-Radial Permanent Magnet and Salient-Pole Electromagnetic Hybrid Excitation Generator for Vehicles
}

\author{
Xueyi Zhang ${ }^{1^{*}} \mathbb{0}$, Qinjun Du², Jinbin Xu' ${ }^{1}$ Yuzhen Zhao ${ }^{1}$ and Shilun Ma ${ }^{1}$
}

\begin{abstract}
With the improvement of vehicles electrical equipment, the existing silicon rectification generator and permanent magnet generator cannot meet the requirement of the electric power consumption of the modern vehicles electrical equipment. It is difficult to adjust the air gap magnetic field of the permanent magnet generator. Consequently, the output voltage is not stable. The silicon rectifying generator has the problems of low efficiency and high failure rate. In order to solve these problems, a new type of hybrid excitation generator is developed in this paper. The developed hybrid excitation generator has a double-radial permanent magnet, a salient-pole electromagnetic combined rotor, and a fractional slot winding stator, where each rotor pole corresponds to 4.5 stator teeth. The equivalent magnetic circuit diagram of permanent magnet rotor and magnetic rotor is established. Magnetic field finite element analysis (FEA) software is used to conduct the modeling and simulation analysis on double-radial permanent magnet magnetic field, salient-pole electro-magnetic magnetic field and hybrid magnetic field. The magnetic flux density mold value diagram and vector diagram are obtained. The diagrams are used to verify the feasibility of this design. The designed electromagnetic coupling regulator controller can ensure the stable voltage export by changing the magnitude and direction of the excitation current to adjust the size of the air gap magnetic field. Therefore, the problem of output voltage instability in the wide speed range and wide load range of the hybrid excitation generator is solved.
\end{abstract}

Keywords: Vehicle, Hybrid excitation generator, Double-radial permanent magnet, Salient-pole electromagnetic, Electromagnetic coupling regulator controller

\section{Introduction}

Generator is a key component of vehicle power system. At present, the main generator used in the vehicle is the silicon rectification generator and permanent magnet generator. The magnetic field of silicon rectification generator is created by electric excitation winding. Most of electric energy through the electric excitation winding is consumed in the form of heat, and only small part of electric energy is converted into magnetic energy for power generation, which causes the low efficiency of the

\footnotetext{
*Correspondence: zhangxueyi@sdut.edu.cn

${ }^{1}$ School of Transportation and Vehicle Engineering, Shandong University of Technology, Zibo 255049, China

Full list of author information is available at the end of the article
}

generator. Permanent magnet generator's magnetic field is created by permanent magnet without any electrical excitation winding, which has advantages of simple structure and reliable operation. However, limited to the current development level of permanent magnet generator, it is difficult to adjust the magnetic characteristics of the generator and maintain the output voltage stable [1, 2]. Permanent magnet generator is mainly used on the vehicle whose generator power is relatively small. While the generator power is too large, costs will be greatly increased and its popularization and application will be affected.

Hybrid excitation generator is a combination of permanent magnets generator and electromagnetic generator [3-8]. The hybrid excitation generator using $\mathrm{Nd}-\mathrm{Fe}-\mathrm{B}$ 
permanent-magnet materials to excite the magnetic field, which makes the specific power of generator increased, field winding current and excitation loss decreased, and efficiency of generator improved. Furthermore, the generator's idle speed performance is better. According to the relationship between the permanent magnetic potential and the electric field potential, the hybrid excitation generator can be divided into two types: series hybrid excitation generator and parallel hybrid excitation generator. In the series hybrid excitation generator, electric field winding is arranged below the permanent magnet of the rotor to form a series structure. Due to the presence of the brush and slip ring structure, the reliability of the generator is reduced [9]. In order to improve the structure of the brush generator, Leonardi et al. [10] put forward a kind of permanent magnet and excitation winding are located on the stator of the series hybrid excitation generator. Cancelled the brush and slip ring, the structure is more simple. But the electric excitation magnetic potential direct affects the permanent magnet and it is prone to irreversible demagnetization. Therefore, scholars have less research on this kind of generator. At present, the research of hybrid excitation generator is mainly concentrated in the parallel hybrid excitation generator. Hoange [11] proposed a hybrid excitation flux-switching generator based on the structure of fluxswitching permanent magnet generator. Many scholars have shown a strong interest in the structure of the motor, and launched a related research [12, 13]. According to the different combinations of permanent magnet and electric field winding, the electromagnetic performance and magnetic field regulation ability of the hybrid excitation flux-switching generator with different topologies were compared and analyzed $[14,15]$. The generator has no permanent magnet or electric field winding on its rotor, and has many advantages of high power density and high efficiency. But the magnetic circuit of the generator is easily saturated, and the cogging torque is larger. A hybrid excitation claw-pole generator was proposed by Professor Qunjing Wang in HeFei University of Technology $[16,17]$. Because the electrical excitation part of the generator adopts the claw-pole structure, the additional air gap is large, the magnetic flux leakage is bigger, and the power density is low. Professor Surong Huang [18] in Shanghai University proposed a hybrid excitation bypass flux generator. The generator is easy to manufacture. However, the electric field winding is installed on the stator side, which results in a larger the electric excitation magnetic circuit reluctance affecting the efficiency of the generator.

In this paper, the double-radial permanent magnet and salient-pole electromagnetic hybrid excitation generator is developed adopting a combined rotor structure. The permanent magnet part is designed as a double radial permanent magnet structure, which can increase the air gap flux in the case of a certain volume of the generator, and increase the power density of the generator. The electric exciting part is designed as a salient electromagnetic structure, which is simpler than that of the traditional claw-pole electromagnetic and is easy to be processed. Consequently, the axial length of the generator is reduced. The double-radial permanent magnet field and the salient-pole electromagnetic magnetic field are used as the main generating part and the auxiliary generating part of the generator, respectively. The salient-pole electromagnetic magnetic field plays the role of increasing or weakening the main magnetic circuit magnetic flux in the hybrid magnetic field. The generator not only has good adjustment characteristic, but also has advantages of high power density, high efficiency and high reliability. It has important application value in the vehicle power system.

\section{Determination of Main Parameters}

The hybrid excitation generator is composed of doubleradial permanent-magnet rotor, salient-pole electrical excitation rotor, stator core, armature winding and other components. Schematic diagram is shown in Figure 1.

\subsection{Double-Radial Permanent-Magnet Rotor}

The structure diagram of double-radial permanent magnet rotor is illustrated in Figure 2. The permanent magnet

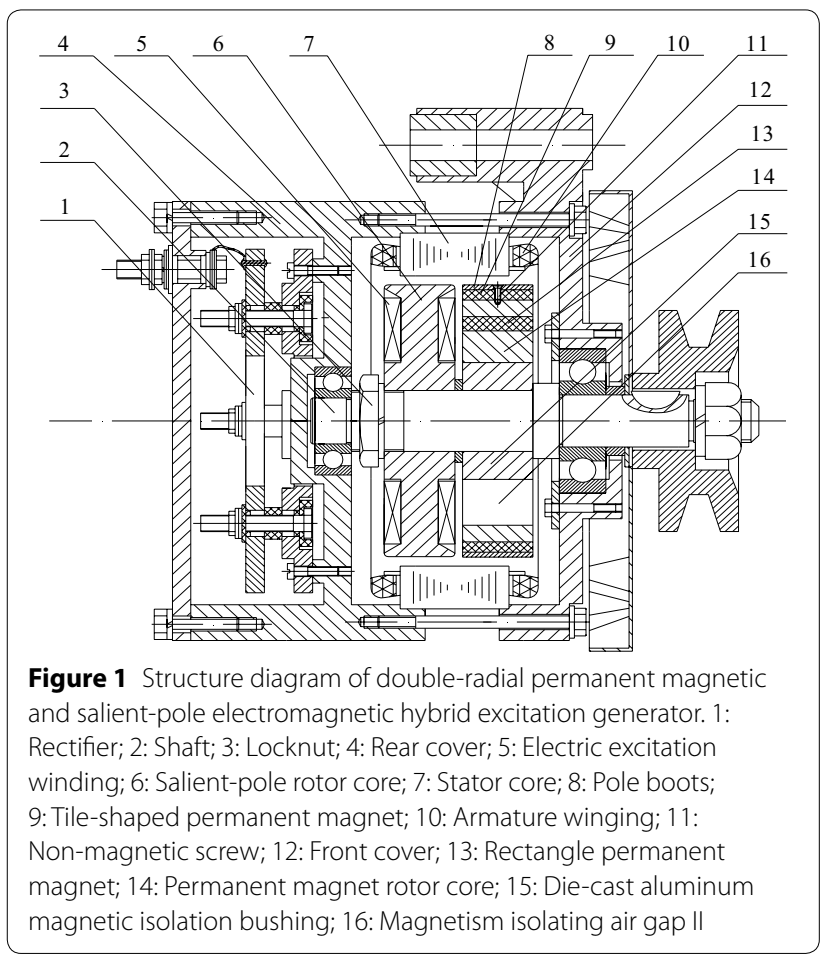




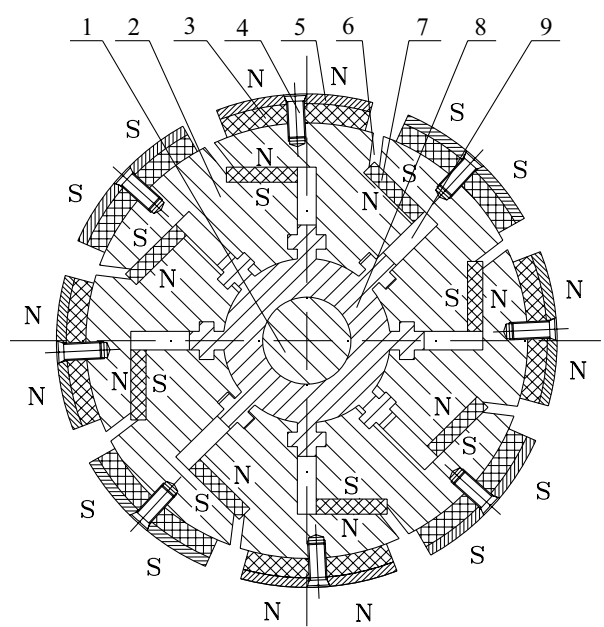

Figure 2 Structure diagram of double-radial permanent magnet rotor. 1: Shaft; 2: Permanent magnet rotor core; 3: Tile-shaped permanent magnet; 4: Non-magnetic screw; 5 : Pole boots; 6 : Magnetism isolating air gap I; 7: Rectangle permanent magnet; 8: Die-cast aluminum magnetic isolation bushing; 9: Magnetism isolating air gap II

of the rotor is composed by tile-shaped permanent magnet and rectangle permanent magnet. The tile-shaped permanent magnet is fixed on the rotor yoke through pole boots by non-magnetic screw, and the rectangle permanent magnet is embedded in the rotor core's rectangular groove. Since the tile-shaped permanent magnet and rectangle permanent magnet provide flux for air-gap together, the air-gap flux density is increased. Magnetism isolating air gaps I and II on rotor core are designed in order to avoid the rectangular permanent magnet appeared magnetic flux leakage by itself.

Volume of the permanent magnet is estimated based on the empirical formula [19]:

$$
V_{\mathrm{m}}^{\prime}=225 \frac{p_{N Y \sigma_{0} K_{\mathrm{ad}} K_{\mathrm{F}}}}{f K_{\mathrm{u}} K_{\mathrm{B}} C(B H)_{\max }},
$$

where $P_{N Y}$ is the power of permanent-magnet, $\sigma_{0}$ is the magnetic leakage coefficient, $K_{\mathrm{ad}}$ is the equivalent coefficient of direct-axis armature reaction, $K_{\mathrm{F}}$ is the multiple of permanent magnet magneto motive force to directaxis armature magneto motive force when the generator short-circuits, $f$ is the frequency of generator, $K_{\mathrm{u}}$ is the voltage waveform coefficient, $K_{\mathrm{B}}$ is the air-gap flux waveform coefficient, $C$ is the maximum magnetic energy utilization coefficient, $(B H)_{\max }$ is the maximum magnetic energy product.

The permanent magnet's theoretical volume is: $V_{\mathrm{m}}^{\prime}=3.46 \times 10^{4} \mathrm{~mm}^{3}$.

The permanent magnet's specific size is determined by the geometric constraints of rotor structure. Geometric

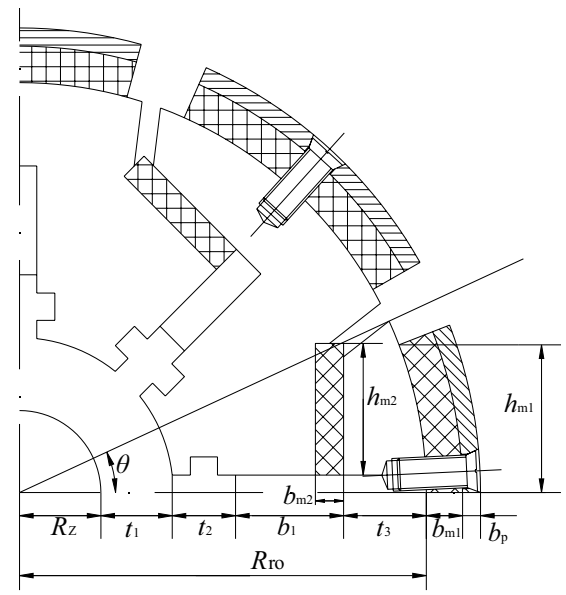

Figure 3 Geometric constraints of permanent magnet thickness

constraints of permanent magnet's thickness are illustrated in Figure 3.

Stator core radius $R_{\mathrm{s} 0}$ and rotor core radius $R_{\mathrm{r} 0}$ of the generator are constant in this design. Permanent magnet's thickness is affected by multiple geometric constraints:

$$
\begin{aligned}
& 0<b_{\mathrm{m} 1}+b_{\mathrm{P}}<R_{\mathrm{s} 0}-R_{\mathrm{r} 0}-\delta, \\
& h_{\mathrm{m} 1}<R_{\mathrm{r} 0} \theta \frac{\pi}{180}, \\
& 0<t_{3}=R_{\mathrm{r} 0}-\frac{h_{\mathrm{m} 2}}{\tan \theta}<R_{\mathrm{r} 0}-\left(R_{\mathrm{z}}+t_{1}+t_{2}\right) .
\end{aligned}
$$

where $b_{\mathrm{m} 1}$ is the thickness of tile-shaped permanent magnet, $b_{\mathrm{P}}$ is the thickness of pole boots, $\delta$ is the air gap length, $\theta$ is the angle between magnetism isolating air gap II and abscissa, $h_{\mathrm{m} 1}$ is half width of tile-shaped permanent magnet, $h_{\mathrm{m} 2}$ is the width of rectangle permanent magnet, $R_{\mathrm{z}}$ is the axis radius, $t_{1}$ is the thickness of magnetic isolation bushing, $t_{2}$ is the length of magnetic isolation bushing bulge, $t_{3}$ is the distance from rectangular permanent magnet to the edge of rotor core.

The actual size of the permanent magnet calculated is shown in Table 1.

\subsection{Salient-Pole Electrical Excitation Rotor}

Electrical excitation rotor is required to generate additional no-load induced electromotive force according to changes in load current in order to compensate for the voltage changes that caused by load current changes. Therefore, the hybrid excitation generator terminal voltage remains constant. For salient pole generator, only the pole shape and electric excitation winding turns need to be designed and calculated. The structure diagram 
Table 1 Size of permanent magnet

\begin{tabular}{lll}
\hline $\begin{array}{l}\text { Permanent magnet } \\
\text { parameter }\end{array}$ & $\begin{array}{l}\text { Tile-shaped permanent } \\
\text { magnet }\end{array}$ & $\begin{array}{l}\text { Rectangle } \\
\text { permanent } \\
\text { magnet }\end{array}$ \\
\hline Thickness $(\mathrm{mm})$ & $b_{\mathrm{m} 1}=2.5$ & $b_{\mathrm{m} 2}=4.0$ \\
Width $(\mathrm{mm})$ & $2 h_{\mathrm{m} 1}=40$ & $h_{\mathrm{m} 2}=15$ \\
Axial length $(\mathrm{mm})$ & $I_{\mathrm{m} 1}=32$ & $I_{\mathrm{m} 2}=32$ \\
\hline
\end{tabular}

of salient-pole electrical excitation rotor is illustrated in Figure 4.

\subsubsection{Determine the Shape of the Salient-Pole}

In the design of salient-pole generator, there are clear requirements of air-gap flux density waveform for the utmost sinusoidal distribution to make output voltage of the generator be sine wave. However, due to the concentration of salient-pole generator excitation winding, the magnetic potential distribution is rectangular wave. Therefore, generally there are no even air gaps for the salient-pole generator. The air gaps on the middle line and the tip of the magnetic pole are designed into the minimum value $\delta_{\min }$ and the maximum value $\delta_{\max }$, respectively. Magnetic pole shape of salient generator is shown in Figure 5.

The air gap flux density waveform is very similar to sine wave when the ratio is: $\delta_{\max }: \delta_{\min }=1.5: 1$. If the ratio is too small, air gap flux density waveform will be pulse shape. If the ratio is too large, leakage flux between adjacent pole boots will be increased. If the pole body width $b_{\mathrm{m}}$ is too small, magnetic flux density is easily reached saturation. If $b_{\mathrm{m}}$ is too large, the space for electric excitation

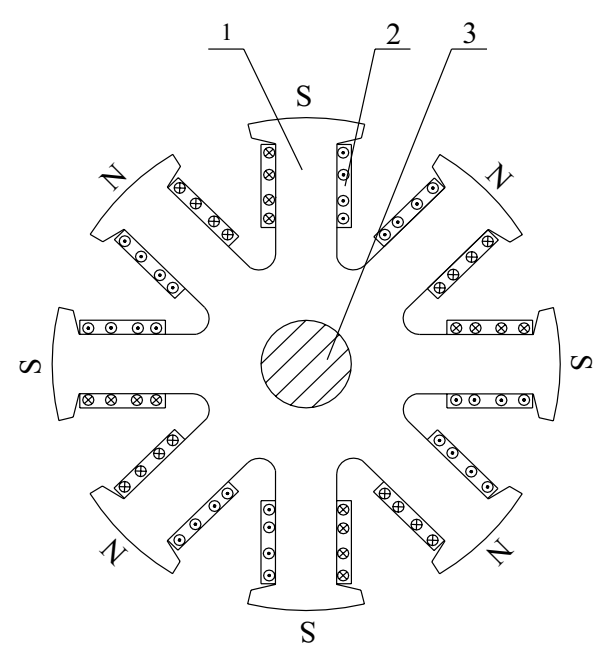

Figure 4 Structure diagram of salient-pole electrical excitation rotor. 1: Salient-pole rotor core; 2: Electric excitation winding; 3: Shaft

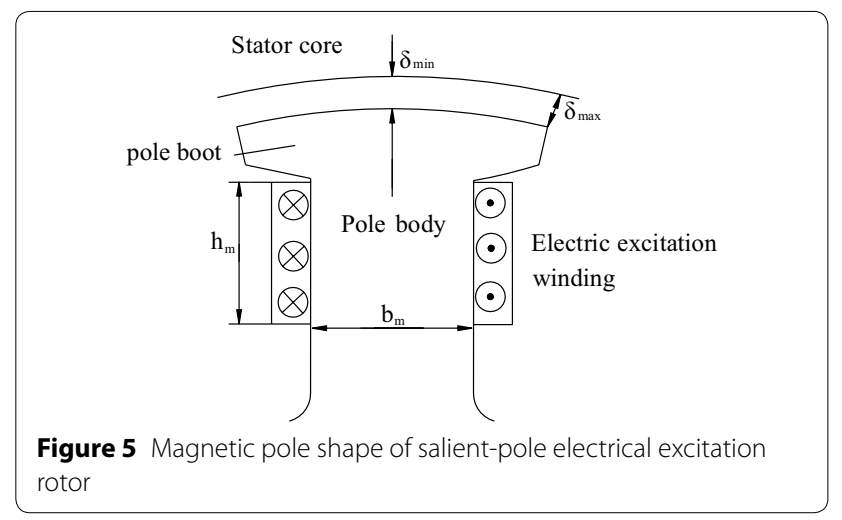

winding will be too small. $b_{\mathrm{m}}$ is determined by the following formula:

$$
b_{\mathrm{m}}=\frac{\frac{2}{\pi} B_{\mathrm{g}} \tau l \sigma_{\mathrm{m}}}{K_{\mathrm{m}} l_{\mathrm{m}} B_{\mathrm{m}}}
$$

where $B_{\mathrm{g}}$ is the peak value of air gap magnetic-flux density sine wave, $\tau$ is the polar distance, $l$ is the salient rotor core length, $\sigma_{\mathrm{m}}$ is the magnetic leakage coefficient of magnetic pole, $K_{\mathrm{m}}$ is the rotor punching sheet laminated coefficient, $l_{\mathrm{m}}$ is the axial length of the rotor pole body, $B_{\mathrm{m}}$ is the control using value of rotor pole body magnetic flux density.

In the above formula, numerator is each magnetic pole magnetic flux of the rotor, and denominator is the magnetic flux that the unit pole body width corresponding body area allowed to pass. The calculation of pole body width $B_{\mathrm{m}}$ is $12 \mathrm{~mm}$.

Rotor pole body height $h_{\mathrm{m}}$ is determined by total crosssectional area of electrical excitation winding. If the height is too small, the space to place electrical excitation winding will not be enough. In this design, the rotor pole body height $h_{\mathrm{m}}$ is $25 \mathrm{~mm}$.

\subsubsection{Calculation of Electrical Excitation Winding}

Electrical excitation winding is spooled on the rotor iron core, and two adjacent windings are spooled on the opposite directions. The numbers of winding turns are equal. Electrical excitation rotor which has $\mathrm{N}$ pole and $S$ pole arranged interval are formed on the neighboring two salient pole surface.

Calculations of electrical excitation winding turns and wire diameter are as follows.

According to Kirchhoff's second law: $\sum H L=N I$, Namely, $\sum \frac{B l}{\mu_{r} \mu_{0}}=N I$, then the following formula can be derived:

$$
\frac{B_{0}}{\mu_{0}} \times l_{0}+\frac{B_{1}}{\mu_{\mathrm{r} 1} \mu_{0}} \times l_{1}+\frac{B_{2}}{\mu_{\mathrm{r} 2} \mu_{0}} \times l_{2}=I \times N,
$$


where $B_{0}$ is the magnetic induction intensity in the air gap, $B_{1}$ is the magnetic induction intensity in silicon steel sheet, $B_{2}$ is the magnetic induction intensity in rotor core, $l_{0}$ is the air gap magnetic path length, $l_{1}$ is the silicon steel sheet magnetic path length, $l_{2}$ is the rotor core magnetic path length, $\mu_{0}$ is the permeability of vacuum, $\mu_{\mathrm{r} 1}$ is the relative permeability of silicon steel sheet, $\mu_{\mathrm{r}}$ is the relative permeability of rotor core, $I$ is the excitation winding current, $N$ is the excitation winding turns.

The calculated number of excitation winding turns is 1868.9 , namely, the number of turns per pole is 233.6 turns. In this design, each pole of electric excitation winding has a turn of 235 .

Electrical excitation winding wire diameter $d_{1}$ :

$$
\frac{\pi}{4} d_{1}^{2}=\frac{I}{J},
$$

where $J$ is the current density of electrical excitation winding wire.

The computation results of $d_{1}$ is $0.48 \mathrm{~mm}$. In this design, $d_{1}$ is assigned the value of $0.51 \mathrm{~mm}$.

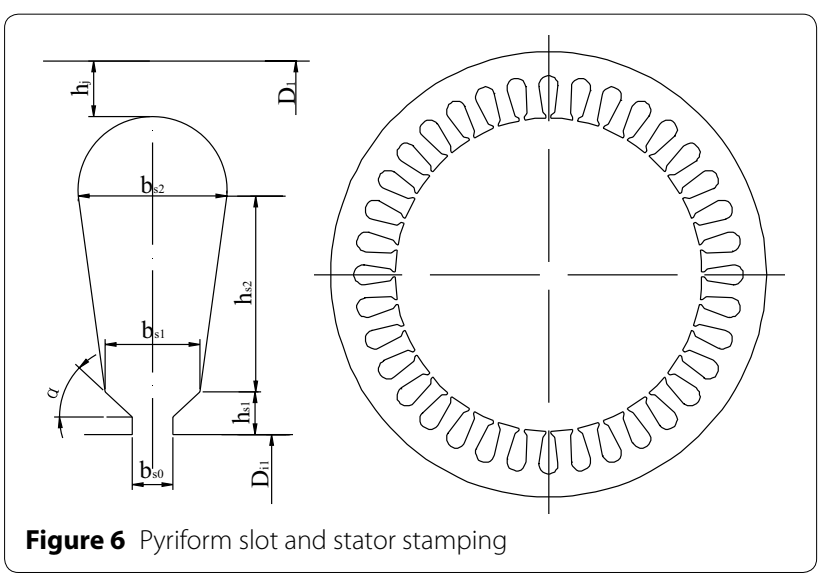

\subsection{Stator Structure Design}

The stator of hybrid excitation generator is designed with 3 -phase, 8-pole and 36 slots, where each rotor pole corresponds to 4.5 stator teeth. This fractional slot winding can not only reduce the high-harmonic content of generator air-gap magnetic field and the stator iron losses, but also make the static magnetic moment of the entire rotor minimum. It greatly reduces the starting resistance torque of the generator. Pyriform slot is selected as the stator slot type in this design. Stator slot type and stator stamping are shown in Figure 6.

Three-phase double-layer fractional-slot winding is used in this design. Schematic diagrams of winding embedded line and fractional slot winding are shown in Figure 7 and Figure 8, respectively.

(1) The armature winding turns are calculated by:

$$
N_{s}=\frac{E_{0}}{4.44 f K_{w} \varphi_{0}},
$$

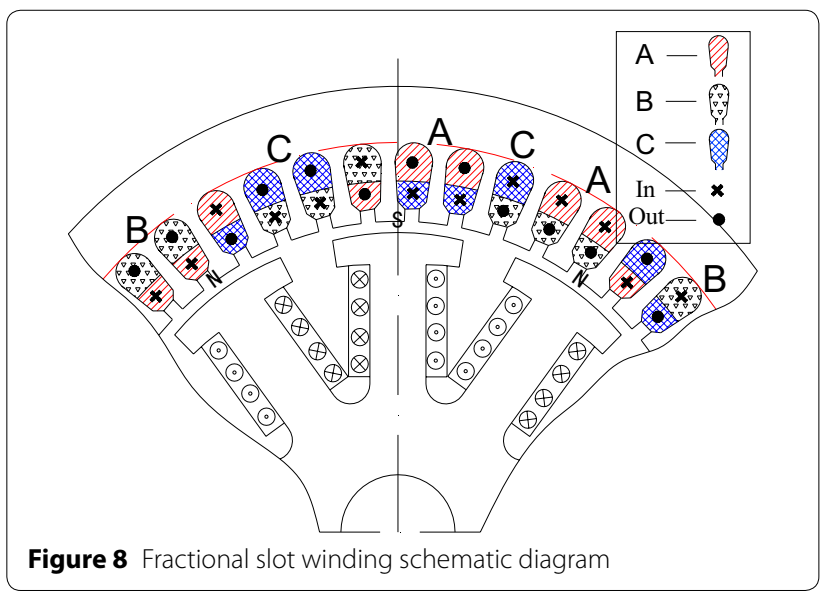

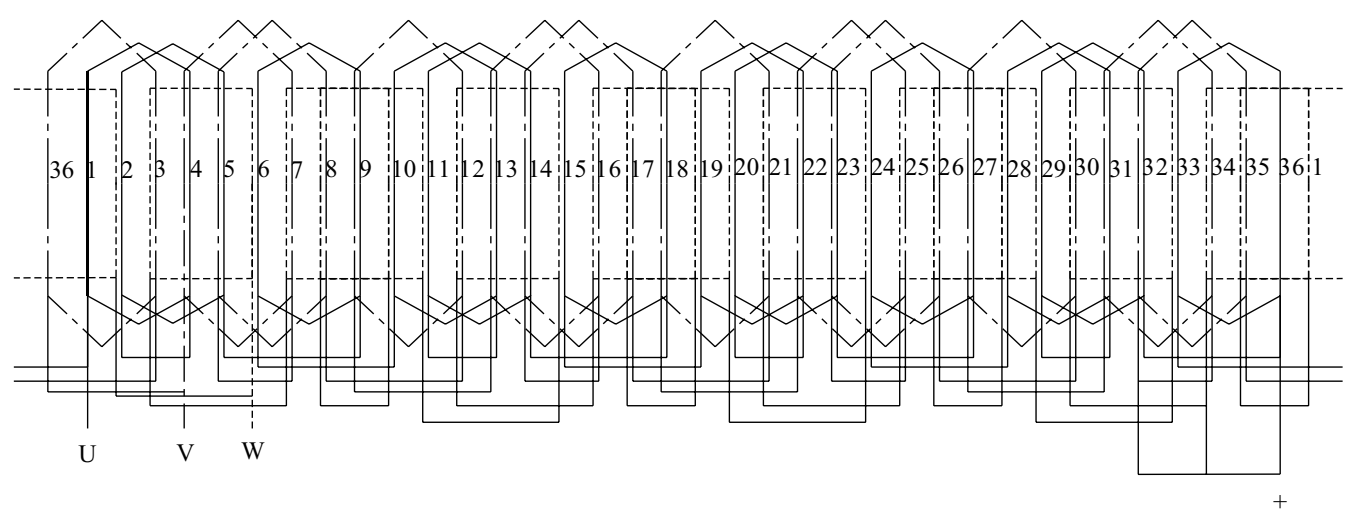

Figure 7 Stator winding embedded line diagram 
where $E_{0}$ is no-load induced electromotive force, $K_{w}$ is armature winding factor, $\varphi_{0}$ is the effective magnetic flux through the armature windings at empty load. The computation result of $N_{s}$ is 72 .

(2) Diameter $d$ of winding conductor is determined by:

$$
A_{\mathrm{Cu}}=\frac{I_{\mathrm{N}}}{a J^{\prime}}
$$

where $A_{\mathrm{Cu}}$ is the wire cut-area, $I_{\mathrm{N}}$ is the rated phase current, $a$ is the number of parallel branch, in this design $a=1$. The computation result of $A_{\mathrm{Cu}}$ is $2.38 \mathrm{~mm}^{2}$. Namely, the diameter $d$ of winding conductor is $1.74 \mathrm{~mm}$. In this design, $d$ is assigned the value of $1.75 \mathrm{~mm}$.

\section{Equivalent Magnetic Circuit Analysis}

\subsection{Hybrid Excitation Generator Equivalent Magnetic Circuit}

The equivalent magnetic circuit diagram [20-22] of double-radial permanent magnet and salient-pole electromagnetic hybrid excitation generator is shown in Figure 9.

In Figure 9, $F_{\mathrm{c} 1}$ is equivalent magnetic potential of tileshaped permanent magnet, $F_{\mathrm{c} 2}$ is equivalent magnetic potential of rectangle permanent magnet, $F_{\mathrm{i}}$ is equivalent magnetic potential of electromagnetic winding, $F_{\text {ad }}$ is longitudinal axis component of armature reaction magnetic potential, $G_{\mathrm{m} 1}$ is equivalent magnetic permeance of tile-shaped permanent magnet, $G_{\mathrm{m} 2}$ is equivalent magnetic permeance of rectangle permanent magnet, $G_{e}$ is equivalent magnetic permeance of electromagnetic winding, $G_{\delta}$ is main air gap permeance, $G_{\mathrm{m} \delta 1}$ is additional air gap permeance between tile-shaped permanent magnet and pole shoe, $G_{\mathrm{m} \delta 2}$ is additional air gap permeance between rotor core and tile-shaped permanent magnet, $G_{\mathrm{m} \delta 3}$ is additional air gap permeance between rotor core and rectangle permanent magnet, $G_{e} \delta 1$ is additional air gap permeance between electromagnetic winding and salient-pole, $G_{\mathrm{P}}$ is pole boots permeance, $G_{\mathrm{t}}$ is stator tooth permeance, $G_{k}$ is salient-pole electromagnetic rotor core permeance, $G_{\mathrm{j} 1}$ is stator yoke permeance, $G_{\mathrm{j} 2}$ is rotor core permeance which is from tile-shaped permanent magnet to rectangle permanent magnet; $G_{j 3}$ is rotor core permeance which is from rectangle permanent magnet to tile-shaped permanent magnet, $G_{m \sigma 1}$ is leakage permeance between tile-shape permanent magnet axial end surface, $G_{\mathrm{m} \sigma 2}$ is leakage permeance between tileshaped permanent magnet side surface, $G_{\mathrm{mo3}}$ is leakage permeance between the two ends of pole shoes, $G_{\text {e } 11}$ is the leakage permeance between the two ends of electric excitation winding, $G_{\mathrm{e} \sigma 2}$ is leakage permeance between electric excitation winding side surface, $F_{\mathrm{m}}$ is total magnetic potential drop between the two ends of tile-shape permanent magnet, $\Phi_{\mathrm{m} \delta}$ is no-load total magnetic flux of tile-shaped permanent magnet, $\Phi_{\mathrm{e} \delta}$ is no-load total magnetic flux of electric excitation winding, $\Phi_{\mathrm{mU}}$ is the no-load effective magnetic flux through the air-gap, $\Phi_{\mathrm{m} \sigma 1}$ is leakage magnetic flux between tile-shape permanent magnet axial end surfaces, $\Phi_{\mathrm{m} \sigma 2}$ is leakage magnetic flux between tile-shape permanent magnet side surfaces, $\Phi_{\mathrm{mo3}}$ is the no-load leakage magnetic flux between the two ends of pole shoes, $\Phi_{\mathrm{e} \sigma 1}$ is leakage magnetic flux that is converted to the two ends of electric excitation winding, $\Phi_{\text {eø2 }}$ is leakage flux between poles which is converted to the two ends of electric excitation winding.

Since the magnetic circuit of double-radial permanent magnet part and salient-pole electromagnetic part is essentially independent of each other, permanent magnet magnetic circuit and electric excitation magnetic circuit are analyzed separately to simplify the analysis process.

\subsection{Analysis of Permanent Magnet Part Equivalent Magnetic Circuit}

In radially magnetized permanent magnet generator, two permanent magnets of a pair of poles are working in tandem status, where each permanent magnet provides each pole's air-gap flux. In double-radial permanent magnet

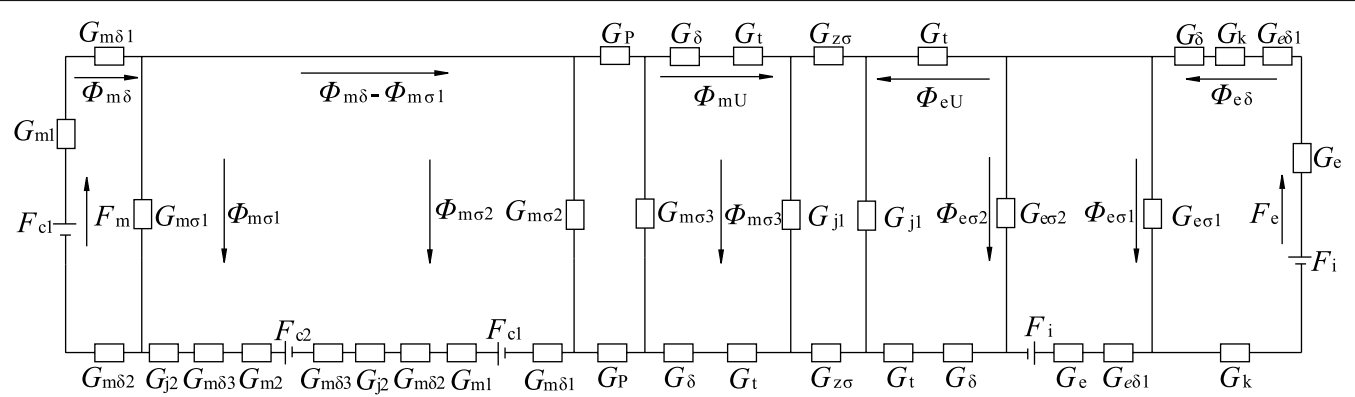

Figure 9 The equivalent magnetic circuit diagram of double-radial permanent magnet and salient-pole electromagnetic hybrid excitation generator 
generator, each pole air gap flux is provided by three permanent magnets. The equivalent magnetic circuit diagram is shown in Figure 10.

Each pole has two tile-shaped permanent magnets and one rectangular permanent magnet to form three magnetic potential sources. In order to facilitate analysis, superposition principle is used on the permanent magnet part equivalent magnetic circuit diagram to transform the equivalent magnetic circuit model in Figure 10 into the model $\mathrm{a}+$ model $\mathrm{b}+$ model $\mathrm{c}$, which is shown in Figure 11. When the generator is in no-load operation: $F_{\mathrm{ad}}=0$.

Namely,

$$
\begin{aligned}
\Phi_{\mathrm{m} \delta} & =\Phi_{\mathrm{m} \delta}^{\prime}+\Phi_{\mathrm{m} \delta}^{\prime \prime}+\Phi_{\mathrm{m} \delta}^{\prime \prime \prime}, \\
\Phi_{\mathrm{m} \sigma 1} & =\Phi_{\mathrm{m} \sigma 1}^{\prime}-\Phi_{\mathrm{m} \sigma 1}^{\prime \prime}-\Phi_{\mathrm{m} \sigma 1}^{\prime \prime \prime}, \\
\Phi_{\mathrm{m} \sigma 2} & =\Phi_{\mathrm{m} \sigma 2}^{\prime}+\Phi_{\mathrm{m} \sigma 2}^{\prime \prime}+\Phi_{\mathrm{m} \sigma 2}^{\prime \prime \prime}, \\
\Phi_{\mathrm{m} \sigma 3} & =\Phi_{\mathrm{m} \sigma 3}^{\prime}+\Phi_{\mathrm{m} \sigma 3}^{\prime \prime}+\Phi_{\mathrm{m} \sigma 3}^{\prime \prime \prime}, \\
\Phi_{\mathrm{mU}} & =\Phi_{\mathrm{mU}}^{\prime}+\Phi_{\mathrm{mU}}^{\prime \prime}+\Phi_{\mathrm{mU}}^{\prime \prime \prime} .
\end{aligned}
$$

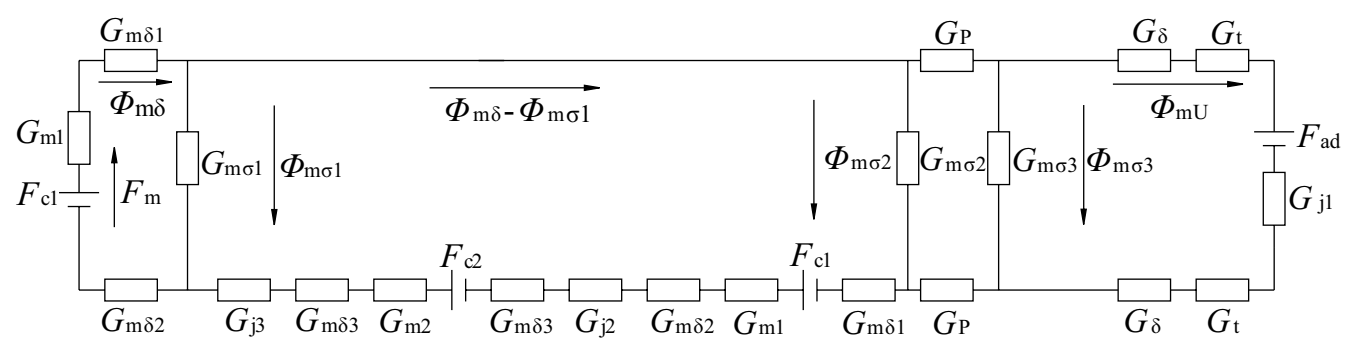

Figure 10 The equivalent magnetic circuit diagram of double-radial permanent magnet part
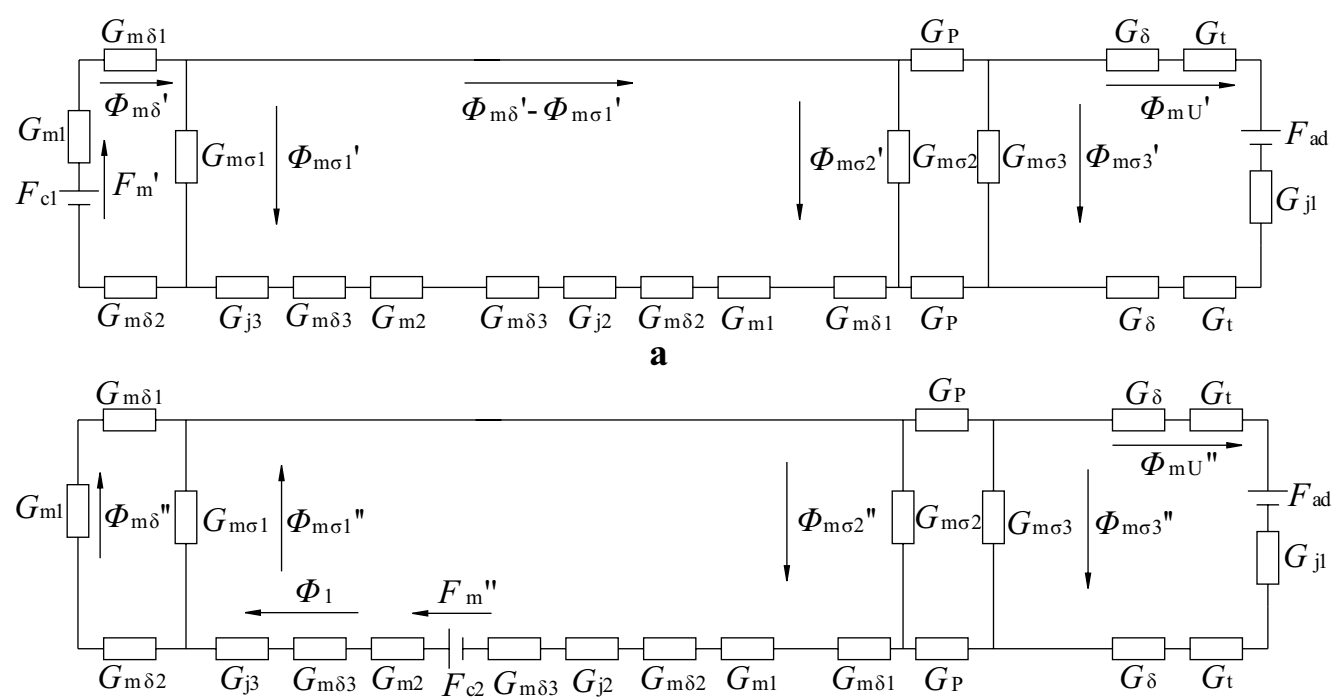

b

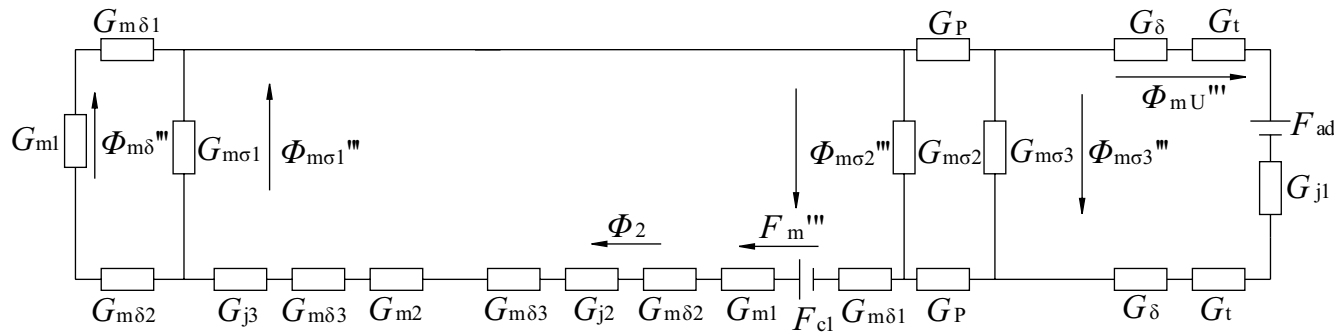

c

Figure 11 Superposition principle diagram of permanent magnet part equivalent magnetic circuit model. a Model a of permanent magnet part equivalent magnetic circuit. b Model b of permanent magnet part equivalent magnetic circuit. c Model c of permanent magnet part equivalent magnetic circuit 
According to Figure 11a, b and c, Ohm's law and Kirchhoff's law of magnetic circuit, Eqs. (10), (11) and (12) can be obtained: magnetic field through the armature winding $\Phi_{\delta 0 y}^{\prime \prime}$ are approximately equal, which meets the design requirements.

$$
\left\{\begin{array}{l}
\Phi_{\mathrm{m} \delta}^{\prime}=\Phi_{\mathrm{m} \sigma 1}^{\prime}+\Phi_{\mathrm{m} \sigma 2}^{\prime}+\Phi_{\mathrm{m} \sigma 3}^{\prime}+\Phi_{\mathrm{mU}}^{\prime} \\
\Phi_{\mathrm{m} \delta}\left(\frac{1}{G_{\mathrm{m} \delta 1}}+\frac{1}{G_{\mathrm{m} \delta 2}}\right)+\Phi_{\mathrm{m} \sigma 1}^{\prime} \frac{1}{G_{\mathrm{m} \sigma 1}}=F_{\mathrm{m}}^{\prime} \\
\left(\Phi_{\mathrm{m} \delta}^{\prime}-\Phi_{\mathrm{m} \sigma 1}^{\prime}\right)\left(\frac{1}{G_{\mathrm{m} 1}}+\frac{1}{G_{\mathrm{m} 2}}+\frac{1}{G_{\mathrm{m} \delta 1}}+\frac{1}{G_{\mathrm{m} \delta 2}}+\frac{2}{G_{\mathrm{m} \delta 3}}+\frac{1}{G_{\mathrm{j} 2}}+\frac{1}{G_{\mathrm{j} 3}}\right) \\
\quad+\Phi_{\mathrm{m} \sigma 2}^{\prime} \frac{1}{G_{\mathrm{m} \sigma 2}}=\Phi_{\mathrm{m} \sigma 1}^{\prime} \frac{1}{G_{\mathrm{m} \sigma 1}}, \\
\left(\Phi_{\mathrm{m} \delta}^{\prime}-\Phi_{\mathrm{m} \sigma 1}^{\prime}-\Phi_{\mathrm{m} \sigma 2}^{\prime}\right) \frac{2}{G_{\mathrm{P}}}+\Phi_{\mathrm{m} \sigma 3}^{\prime} \frac{1}{G_{\mathrm{m} \sigma 3}}=\Phi_{\mathrm{m} \sigma 2}^{\prime} \frac{1}{G_{\mathrm{m} \sigma 2}}, \\
\Phi_{\mathrm{m} U}^{\prime}\left(\frac{2}{G_{\delta}}+\frac{2}{G_{\mathrm{t}}}+\frac{1}{G_{\mathrm{j} 1}}\right)+F_{\mathrm{ad}}=\Phi_{\mathrm{m} \sigma 3}^{\prime} \frac{1}{G_{\mathrm{m} \sigma 3}},
\end{array}\right.
$$

$$
\left\{\begin{array}{l}
\Phi_{\mathrm{m} \sigma 1}^{\prime \prime}+\Phi_{\mathrm{m} \delta}^{\prime \prime}=\Phi_{\mathrm{m} \sigma 2}^{\prime \prime}+\Phi_{\mathrm{m} \sigma 3}^{\prime \prime}+\Phi_{\mathrm{mU}}^{\prime \prime}=\Phi_{1}, \\
\Phi_{1}\left(\frac{1}{G_{\mathrm{m} \delta 1}}+\frac{1}{G_{\mathrm{m} \delta 2}}+\frac{2}{G_{\mathrm{m} \delta 3}}+\frac{1}{G_{\mathrm{m} 1}}+\frac{1}{G_{\mathrm{j} 2}}+\frac{1}{G_{\mathrm{j} 3}}\right) \\
\quad+\Phi_{\mathrm{m} \sigma 1}^{\prime \prime} \frac{1}{G_{\mathrm{m} \sigma 1}}+\Phi_{\mathrm{m} \sigma 2}^{\prime \prime} \frac{1}{G_{\mathrm{m} \sigma 2}}=F_{\mathrm{m}}^{\prime \prime} \\
\Phi_{\mathrm{m} \delta}^{\prime \prime}\left(\frac{1}{G_{\mathrm{m} \delta 1}}+\frac{1}{G_{\mathrm{m} \delta 2}}+\frac{1}{G_{\mathrm{m} 1}}\right)=\Phi_{\mathrm{m} \sigma 1}^{\prime \prime} \frac{1}{G_{\mathrm{m} \sigma 1}} \\
\left(\Phi_{1}-\Phi_{\mathrm{m} \sigma 2}^{\prime \prime}\right) \frac{2}{G_{\mathrm{P}}}+\Phi_{\mathrm{m} \sigma 3}^{\prime \prime} \frac{1}{G_{\mathrm{m} \sigma 3}}=\Phi_{\mathrm{m} \sigma 2}^{\prime \prime} \frac{1}{G_{\mathrm{m} \sigma 2}} \\
\Phi_{\mathrm{m} U}^{\prime \prime}\left(\frac{2}{G_{\delta}}+\frac{2}{G_{\mathrm{t}}}+\frac{1}{G_{\mathrm{j} 1}}\right)+F_{\mathrm{ad}}=\Phi_{\mathrm{m} \sigma 3}^{\prime \prime} \frac{1}{G_{\mathrm{m} \sigma 3}}
\end{array}\right.
$$

$$
\left\{\begin{array}{l}
\Phi_{\mathrm{m} \sigma 1}^{\prime \prime \prime}+\Phi_{\mathrm{m} \delta}^{\prime \prime \prime}=\Phi_{\mathrm{m} \sigma 2}^{\prime \prime \prime}+\Phi_{\mathrm{m} \sigma 3}^{\prime \prime \prime}+\Phi_{\mathrm{mU}}^{\prime \prime \prime}=\Phi_{2}, \\
\Phi_{2}\left(\frac{1}{G_{\mathrm{m} \delta 1}}+\frac{1}{G_{\mathrm{m} \delta 2}}+\frac{2}{G_{\mathrm{m} \delta 3}}+\frac{1}{G_{\mathrm{m} 2}}+\frac{1}{G_{\mathrm{j} 2}}+\frac{1}{G_{\mathrm{j} 3}}\right) \\
\quad+\Phi_{\mathrm{m} \sigma 1}^{\prime \prime \prime} \frac{1}{G_{\mathrm{m} \sigma 1}}+\Phi_{\mathrm{m} \sigma 2}^{\prime \prime \prime} \frac{1}{G_{\mathrm{m} \sigma 2}}=F_{\mathrm{m}}^{\prime \prime \prime}, \\
\Phi_{\mathrm{m} \delta}^{\prime \prime \prime}\left(\frac{1}{G_{\mathrm{m} \delta 1}}+\frac{1}{G_{\mathrm{m} \delta 2}}+\frac{1}{G_{\mathrm{m} 1}}\right)=\Phi_{\mathrm{m} \sigma 1}^{\prime \prime \prime} \frac{1}{G_{\mathrm{m} \sigma 1}} \\
\left(\Phi_{2}-\Phi_{\mathrm{m} \sigma 2}^{\prime \prime \prime}\right) \frac{2}{G_{\mathrm{P}}}+\Phi_{\mathrm{m} \sigma 3}^{\prime \prime \prime} \frac{1}{G_{\mathrm{m} \sigma 3}}=\Phi_{\mathrm{m} \sigma 2}^{\prime \prime \prime} \frac{1}{G_{\mathrm{m} \sigma 2}} \\
\Phi_{\mathrm{m}}^{\prime \prime \prime}\left(\frac{2}{G_{\delta}}+\frac{2}{G_{\mathrm{t}}}+\frac{1}{G_{\mathrm{j} 1}}\right)+F_{\mathrm{ad}}=\Phi_{\mathrm{m} \sigma 3}^{\prime \prime \prime} \frac{1}{G_{\mathrm{m} \sigma 3}}
\end{array}\right.
$$

The calculated no-load effective magnetic flux $\Phi_{\mathrm{mU}}$ and the estimated effective magnetic flux of permanent

\subsection{Analysis of Electrical Excitation Part Equivalent Magnetic Circuit}

The excitation winding is equivalent to a magnetomotive force source $F_{\mathrm{i}}$ and a constant internal magnetic permeance $G_{\mathrm{e}}$. Electrical excitation portion provides main flux $\Phi_{\mathrm{e} \delta}$ and leakage flux $\Phi_{\mathrm{e} \sigma}$ to the outside magnetic circuit, and the corresponding permeance is divided into main permeance $G_{\mathrm{e} \delta}$ and leakage permeance $G_{\mathrm{e} \sigma}$. In salientpole electrical excitation generator, electrical excitation windings of a pair poles are working in tandem status. The equivalent magnetic circuit diagram of salient-pole electrical excitation is shown in Figure 12.

The superposition principle is used to transform the equivalent magnetic circuit model in Figure 12 into the model $\mathrm{a}+$ model $\mathrm{b}$ in Figure 13. When the generator is in no-load operation: $F_{\mathrm{ad}}=0$.

Namely,

$$
\begin{aligned}
\Phi_{\mathrm{e} \delta} & =\Phi_{\mathrm{e} \delta}^{\prime}-\Phi_{\mathrm{e} \delta}^{\prime \prime}, \\
\Phi_{\mathrm{e} \sigma 1} & =\Phi_{\mathrm{e} \sigma 1}^{\prime}-\Phi_{\mathrm{e} \sigma 1}^{\prime \prime}, \\
\Phi_{\mathrm{e} \sigma 2} & =\Phi_{\mathrm{e} \sigma 2}^{\prime}+\Phi_{\mathrm{e} \sigma 2}^{\prime \prime} \\
\Phi_{\mathrm{eU}} & =\Phi_{\mathrm{eU}}^{\prime}+\Phi_{\mathrm{eU}}^{\prime \prime} .
\end{aligned}
$$

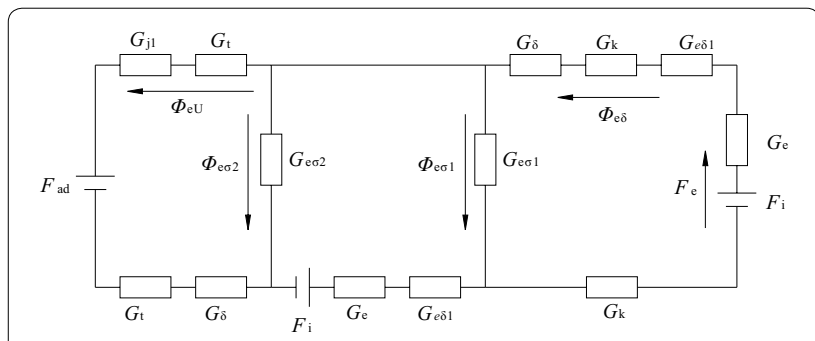

Figure 12 Salient-pole electrical excitation equivalent magnetic circuit diagram 


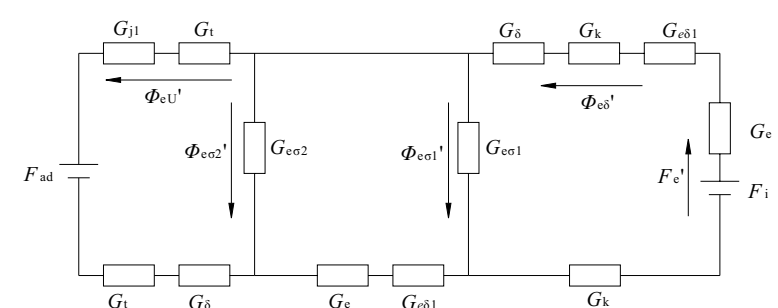

a

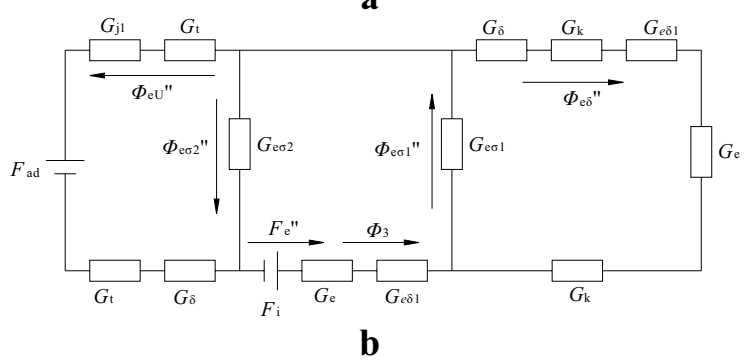

Figure 13 Electrical excitation equivalent magnetic circuit model superposition principle diagram. a Model a of electrical excitation part equivalent magnetic circuit. b Model b of electrical excitation part equivalent magnetic circuit

According to Figure 13a and b, Ohm's law and Kirchhoff's law of magnetic circuit, Eqs. (13) and (14) can be obtained:

$$
\begin{aligned}
& \left\{\begin{array}{l}
\Phi_{\mathrm{e} \delta}^{\prime}=\Phi_{\mathrm{e} \sigma 1}^{\prime}+\Phi_{\mathrm{e} \sigma 2}^{\prime}+\Phi_{\mathrm{eU}}^{\prime}, \\
F_{\mathrm{e}}^{\prime}=\Phi_{\mathrm{e} \delta}^{\prime}\left(\frac{2}{G_{\mathrm{k}}}+\frac{1}{G_{\delta}}+\frac{1}{G_{\mathrm{e} \delta 1}}\right)+\Phi_{\mathrm{e} \sigma 1}^{\prime} \frac{1}{G_{\mathrm{e} \sigma 1}}, \\
\Phi_{\mathrm{e} \sigma 1}^{\prime} \frac{1}{G_{\mathrm{e} \sigma 1}}=\left(\Phi_{\mathrm{e} \delta}^{\prime}-\Phi_{\mathrm{e} \sigma 1}^{\prime}\right)\left(\frac{1}{G_{\mathrm{e}}}+\frac{1}{G_{\mathrm{e} \delta 1}}\right)+\Phi_{\mathrm{e} \sigma 2}^{\prime} \frac{1}{G_{\mathrm{e} \sigma 2}} \\
\Phi_{\mathrm{e} \sigma 2}^{\prime} \frac{1}{G_{\mathrm{e} \sigma 2}}=\Phi_{\mathrm{e} U}^{\prime}\left(\frac{2}{G_{\mathrm{t}}}+\frac{1}{G_{\delta}}+\frac{1}{G_{\mathrm{j} 1}}\right)+F_{\mathrm{ad}},
\end{array}\right. \\
& \left\{\begin{array}{l}
\Phi_{\mathrm{e} \sigma 1}^{\prime \prime}+\Phi_{\mathrm{e} \delta}^{\prime \prime}=\Phi_{\mathrm{e} \sigma 2}^{\prime \prime}+\Phi_{\mathrm{e} U}^{\prime \prime}=\Phi_{3}, \\
F_{\mathrm{e}}^{\prime \prime}=\Phi_{3}\left(\frac{1}{G_{\mathrm{e}}}+\frac{1}{G_{\mathrm{e} \delta 1}}\right)+\Phi_{\mathrm{e} \sigma 1}^{\prime \prime} \frac{1}{G_{\mathrm{e} \sigma 1}}+\Phi_{\mathrm{e} \sigma 2}^{\prime \prime} \frac{1}{G_{\mathrm{e} \sigma 2}} \\
\Phi_{\mathrm{e} \sigma 1}^{\prime \prime} \frac{1}{G_{\mathrm{e} \sigma 1}}=\Phi_{\mathrm{e} \delta}^{\prime \prime}\left(\frac{2}{G_{\mathrm{k}}}+\frac{1}{G_{\delta}}+\frac{1}{G_{\mathrm{e}}}+\frac{1}{G_{\mathrm{e} \delta 1}}\right), \\
\Phi_{\mathrm{e} \sigma 2}^{\prime \prime} \frac{1}{G_{\mathrm{e} \sigma 2}}=\Phi_{\mathrm{e} \mathrm{U}}^{\prime \prime}\left(\frac{2}{G_{\mathrm{t}}}+\frac{1}{G_{\delta}}+\frac{1}{G_{\mathrm{j} 1}}\right)+F_{\mathrm{ad}} .
\end{array}\right.
\end{aligned}
$$

The calculated no-load effective magnetic flux $\Phi_{\mathrm{mU}}$ is less than the estimated effective magnetic flux of permanent magnetic field through the armature winding $\Phi_{\delta 0 y}^{\prime \prime}$. The reason is that the magnetic flux $\Phi_{\delta 0 d}^{\prime \prime}$ is saturated. The magnetic flux density of the Silicon steel is used as the parameter value for the estimation. The actual value is less than the estimated value, which explains magnetic

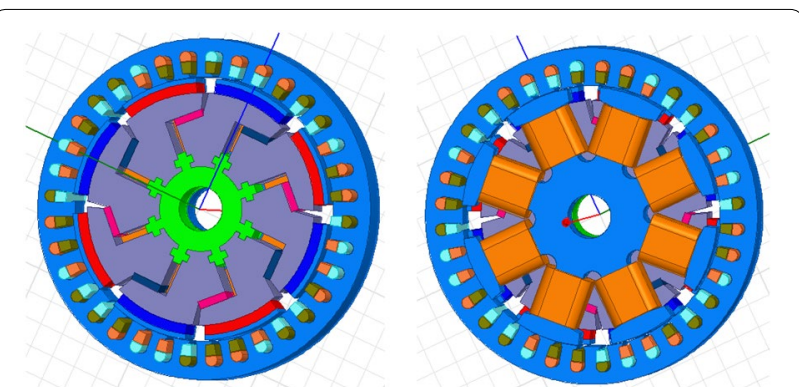

Figure 14 Three-dimensional model of double-radial permanent magnet and salient-pole electromagnetic hybrid excitation generator

field density is produced by the electric field winding current, which does not reached the saturated condition of silicon steel. This design complies with the operational requirements.

\section{Magnetic Field Simulation Analysis and Performance Test}

\subsection{Simulation Models}

The mathematical model for magnetic field analysis is established based on Maxwell equations [23, 24]:

$$
\left\{\begin{array}{l}
\oint_{l} H \cdot \mathrm{d} l=\int_{S} J \cdot \mathrm{d} S+\frac{\partial}{\partial t} \int_{S} D \cdot \mathrm{d} S \\
\oint_{l} E \cdot \mathrm{d} l=-\frac{\partial}{\partial t} \int_{S} B \cdot \mathrm{d} S \\
\oint_{S} B \cdot \mathrm{d} S=0 \\
\oint_{S} D \cdot \mathrm{d} S=\int_{V} \rho \cdot \mathrm{d} V
\end{array}\right.
$$

In the above equations, the relationships between amounts of field are: $D=\varepsilon E, B=\mu H, J=\sigma E$.

The electromagnetic field wave equations are derived from the wave equation using vector magnetic potential as field variable functions, where the wave equation uses scalar function as field variable functions.

$$
\left\{\begin{array}{c}
\nabla^{2} A-\mu \varepsilon \frac{\partial^{2} A}{\partial t^{2}}=-\mu J, \\
\nabla^{2} \phi-\mu \varepsilon \frac{\partial^{2} \phi}{\partial t^{2}}=-\frac{\rho}{\varepsilon} .
\end{array}\right.
$$

The 3D model shown in Figure 14 is for hybrid excitation generator of double-radial permanent magnet and salient-pole electromagnetic. The 3D model is obtained by the following process: constructing geometric models, defining and assigning material properties, defining and loading the excitation source and 
the boundary conditions, solving option parameter and post-processing.

\subsection{Simulation Analysis of the Model}

When the salient-pole electromagnetic rotor pass through with no current, forward current, or reverse current respectively, the diagram of magnetic flux density mold value and magnetic flux density vector are shown in Figure 15a, b and c, respectively.

As shown in Figure 15a, when there is no current in the salient-pole electromagnetic rotor, the air gap magneticflux of double-radial permanent magnet and salient-pole
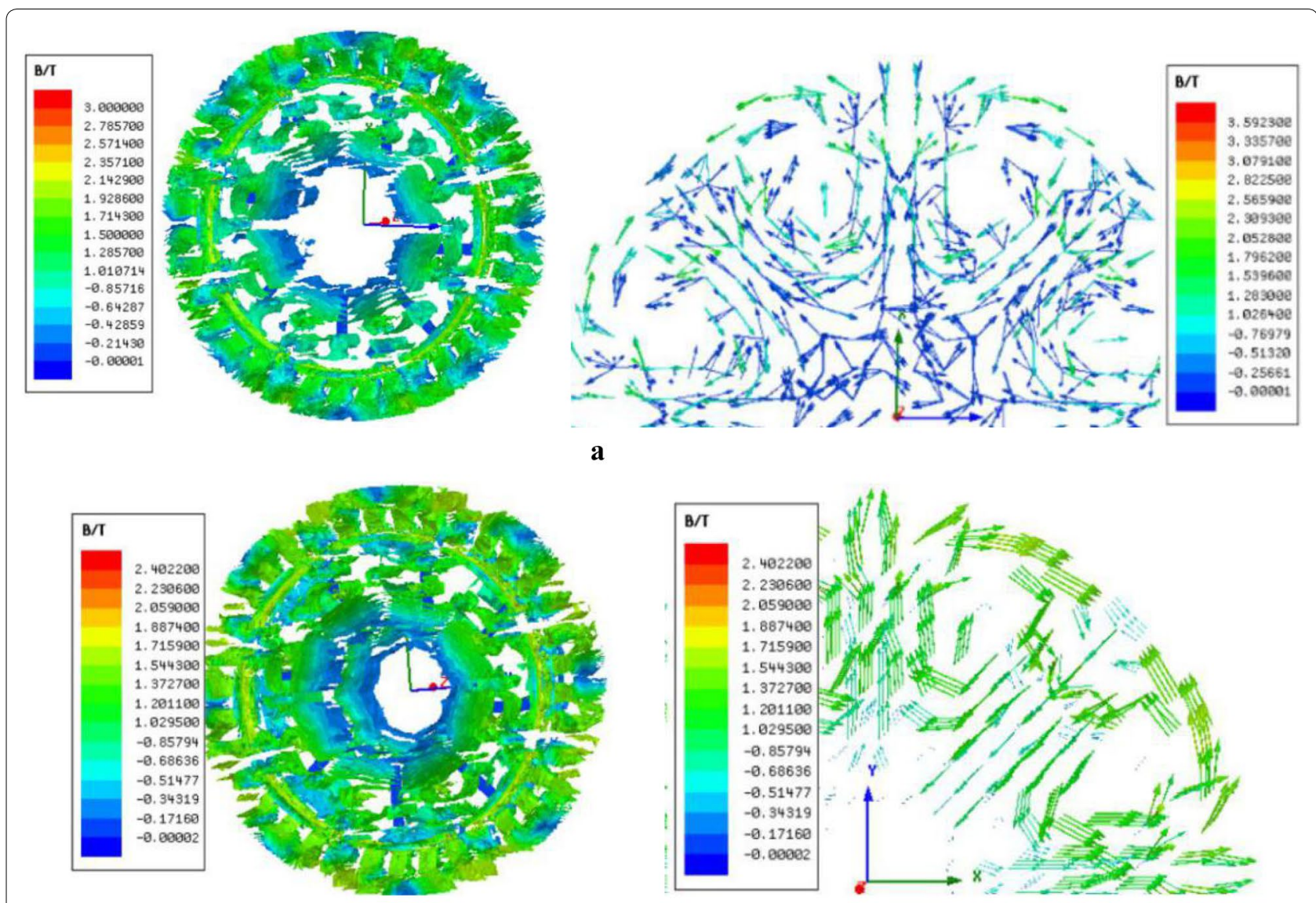

b
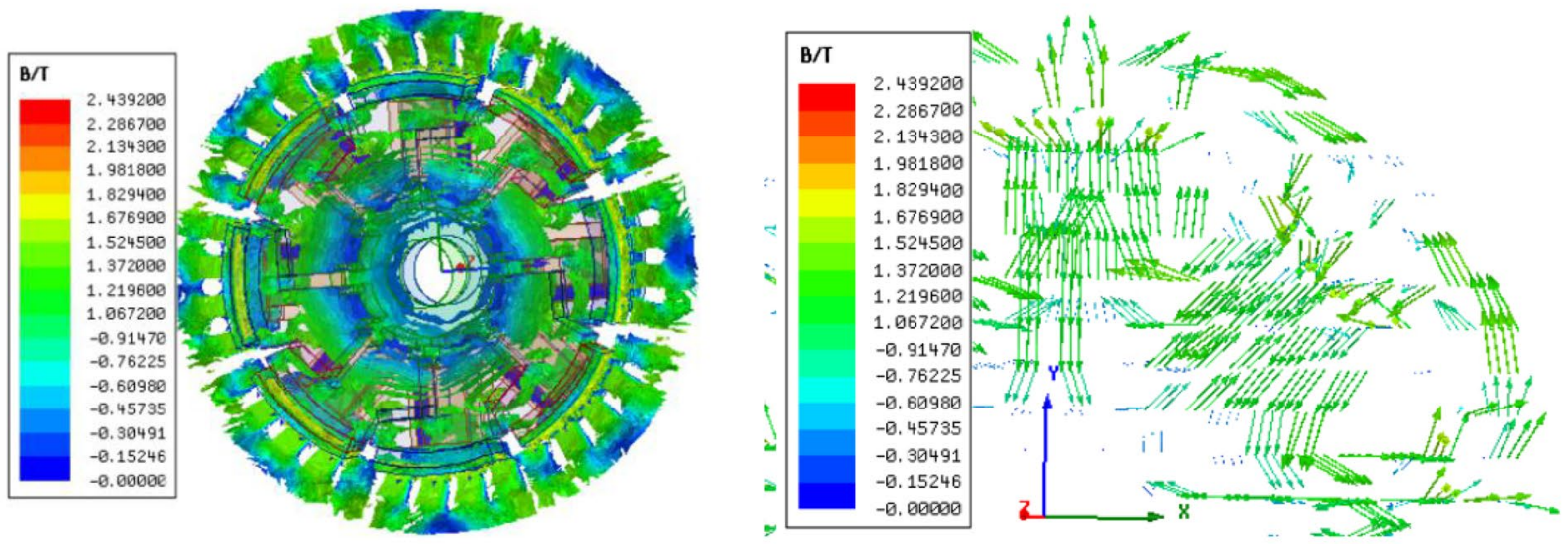

c

Figure 15 The magnetic flux density mold value diagram and vector diagram when electromagnetic rotor passed through with no current (a), forward current (b) and reverse current (c) 


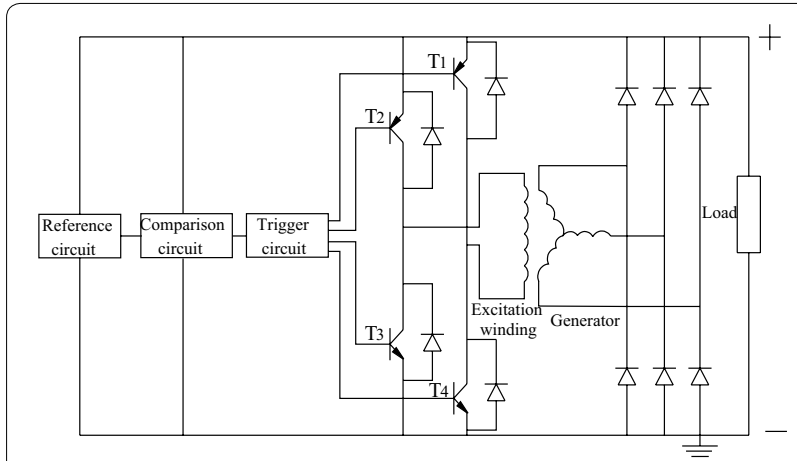

Figure 16 Circuit principle diagram of electromagnetic coupling regulator controller

electromagnetic hybrid excitation generator is provided by the double radial permanent magnetic field, where the air gap magnetic-flux density is small. As shown in Figure $15 \mathrm{~b}$, when the salient-pole electromagnetic rotor pass through with forward current, the generator air gap magnetic-flux is provided by the double-radial permanent magnetic field and salient-pole electromagnetic magnetic field, where salient-pole electromagnetic magnetic field plays a role in increasing magnetic field and the magnetic-flux density is increasing. As shown in Figure 15c, when the salient-pole electromagnetic rotor pass through with reverse current, the generator air gap magnetic-flux is provided by the double-radial permanent magnetic field and salient-pole electromagnetic magnetic field, where salient-pole electromagnetic magnetic field plays a role in reducing magnetic field and air gap magnetic-flux density is decreasing.

The simulation results of the 3D model show that the size of air gap magnetic-flux density can be adjusted by changing the magnitude and direction of the current to achieve the purpose of stabilizing output voltage.

\subsection{Electromagnetic Coupling Regulator Controller}

The target of stable voltage is $28 \mathrm{~V}$ for double-radial permanent magnet and salient-pole electromagnetic hybrid excitation generator in this design. The electromagnetic coupling regulator controller is used to ensure stable voltage export of the hybrid excitation generator in a wide range of speed and load state. Electromagnetic coupling regulator controller consists of reference circuit, comparison circuit, trigger circuit and $\mathrm{H}$-bridge control circuit [25]. According to the changes of hybrid excitation generator output voltage, the electromagnetic coupling regulator controller can change the magnitude and direction of the electromagnetic winding current to adjust the size of the combined magnetic field in the armature winding in order
Table 2 Results of the generator output voltage

\begin{tabular}{lll}
\hline Speed $(\mathbf{r} / \mathbf{m i n})$ & Load power $(\mathbf{k W})$ & $\begin{array}{l}\text { Prototype } \\
\text { voltage }(\mathbf{V})\end{array}$ \\
\hline 2000 & 1.9 & 27.5 \\
& 2.0 & 27.3 \\
& 2.1 & 27.2 \\
4000 & 1.9 & 28.3 \\
& 2.0 & 28.1 \\
4800 & 2.1 & 28.0 \\
& 1.9 & 28.4 \\
& 2.0 & 28.2 \\
& 2.1 & 28.1 \\
\hline
\end{tabular}

to export stable voltage. The circuit principle diagram of electromagnetic coupling regulator controller is shown in Figure 16.

When the engine speed is too low and the hybrid excitation generator output voltage is lower than 28 $\mathrm{V}$, the electromagnetic coupling regulator controller controls the electric excitation winding to be passed through by forward current in order to generate magnetic field, which can be superimposed on permanent magnetic field and will cause increase of the effective magnetic field in the armature winding. Eventually, it will lead to the ascending of hybrid excitation generator output voltage. When the hybrid excitation generator output voltage is higher than $28 \mathrm{~V}$, the electromagnetic coupling regulator controller controls the electric excitation winding to be passed through by reverse current. Then, the generated magnetic field will weaken the permanent magnetic field, which causes decrease of the effective magnetic field in the armature winding. Eventually, it will lead to the reducing of hybrid excitation generator output voltage. It can ensure the hybrid excitation generator to export stable voltage in a wide range of speed and load states. The function of components of electromagnetic coupling regulator controller is as follows.

Reference circuit uses the resistor divider type bias circuit, taking the midpoint of the two voltage-division resistances as the voltage operating point. In order to prevent the changes of stabilivolt value caused by the operating point drifting, usually two zener diode anodes are used in series connection for the temperature compensation.

Comparison circuit utilizes the feature that zener diode works in the reverse breakdown region, when the voltage is less than the stabilivolt value of zener diode where it does not breakover. According to the zener diode breakover or not, two audions alternately will be turned on and turned off, and control signals are sent. 
Trigger circuit can control the H-bridge arm to turn on or off according to the signal emitted by the comparison circuit.

$\mathrm{H}$-bridge control circuit receives the signal provided by trigger circuit to make the two bridge arm alternately turned on or off. Thereby, it provides forward or reverse excitation current for electric excitation winding.

\subsection{Performance Test}

In this design, hybrid excitation generator rated voltage is $28 \mathrm{~V}$, rated power is $5 \mathrm{~kW}$, and rated speed is $4000 \mathrm{r} / \mathrm{min}$. Permanent magnet materials is NTP-240SH $[26,27]$, and its remanent flux density $\mathrm{Br}$ is $1.12 \mathrm{~T}$. The magnetic field strength $H c$ is $804 \mathrm{kA} / \mathrm{m}$, and the maximum energy product $(B H)_{\max }$ is $223 \mathrm{~kJ} / \mathrm{m}^{3}$. Under the conditions of load power is $1.9 \mathrm{~kW}, 2.0 \mathrm{~kW}$ and $2.1 \mathrm{~kW}$, the newly developed hybrid excitation generator is tested from low speeds to high speeds. The results are shown in Table 2.

As seen from Table 2, the performance indicators have reached the design requirements when the generator speed varies from $2000 \mathrm{r} / \mathrm{min}$ to $4800 \mathrm{r} / \mathrm{min}$ and the load power varies from $1.9 \mathrm{~kW}$ to $2.1 \mathrm{~kW}$. The output voltage steadies at 27.2-28.4 V.

\section{Conclusions}

(1) Hybrid excitation generator is composed by combined rotor and fractional slot winding stator. Double-radial permanent magnet and salient-pole electromagnetic share one armature winding, the generated magnetic field synthesizes in the air gap. Per rotor pole corresponds to 4.5 stator teeth. The fractional slot winding used can not only reduce the high-harmonic content of generator air-gap magnetic field and stator iron losses, but also make the static magnetic moment of the entire rotor minimum.

(2) Equivalent magnetic circuit method is used to calculate the equivalent magnetic circuit numerical model of the double-radial permanent magnet and salient-pole electromagnetic hybrid excitation generator. Finite element analysis software is used to simulate and analyze the hybrid magnetic field. The results of numerical calculation and simulation are basically identical, which proves the rationality of the proposed design scheme.

(3) The electromagnetic coupling regulator controller is developed, which stabilize the output voltage between $27.2 \mathrm{~V}$ and $28.4 \mathrm{~V}$ by controlling the magnitude and direction of the electromagnetic winding current. It has excellent voltage stabilizing performances.

\section{Authors' Contributions}

$X Z$ was in charge of the whole trial; QD and JX wrote the manuscript; YZ and SM assisted with sampling and laboratory analyses. All authors read and approved the final manuscript.

\section{Author Details}

1 School of Transportation and Vehicle Engineering, Shandong University of Technology, Zibo 255049, China. ${ }^{2}$ School of Electronic and Electrical Engineering, Shandong University of Technology, Zibo 255049, China.

\section{Authors' Information}

Xueyi Zhang, born in 1963, is currently a professor at School of Transportation and Vehicle Engineering, Shandong University of Technology, China. He received his PhD degree from Shandong University of Science and Technology University, in 2011. His research interests include vehicle electrical and control technology, electric vehicle driving system and control technology. He is a national candidate of Millions of Talents and he enjoys State Department special allowance. He obtained the second award of national technical invention and six items of the second prizes at provincial and ministerial level. He has 25 authorized patents. He has released 112 papers and published 5 monographs. He was named the Taishan scholar in 2015.

Qinjun Du, born in 1967, is currently a professor at School of Electrical and Electronic Engineering, Shandong University of Technology, China. He received his PhD degree from Shandong University of Science and Technology University, in 2011. His research interests include automatic device and control technology of power system, vehicle electrical and electronic technology, robot control technology. He won the young experts with outstanding contributions in Shandong Province. He obtained the second award of national technical invention and three items of the second prizes at provincial and ministerial level. He has released 43papers.

Jinbin Xu, born in 1992, is currently a master candidate at School of Transportation and Vehicle Engineering, Shandong University of Technology, China. His research interests include vehicle electrical and electronic, electric vehicle technologies.

Yuzhen Zhao, born in 1991, is currently a master candidate at School of Transportation and Vehicle Engineering, Shandong University of Technology, China. Her research interests include vehicle electrical and electronic, electric vehicle technologies.

Shilun Ma, born in 1989, is currently a PhD candidate at School of Transportation and Vehicle Engineering, Shandong University of Technology, China. $\mathrm{His}$ research interests include vehicle electrical and electronic, electric vehicle technologies.

\section{Competing Interests}

The authors declare that they have no competing interests.

\section{Funding}

Supported by National Natural Science Foundation of China (Grant No. 51507096), and Shandong Provincial Natural Science Foundation of China (Grant No. ZR2014JL035).

Received: 21 October 2017 Accepted: 20 February 2019 Published online: 10 April 2019

\section{References}

[1] Xueyi Zhang, Liwei Shi, Yujuan Wang. Design and stabilivolt analysis of $\mathrm{Nd}$-Fe-B permanent magnet generator for electric vehicle range extender. International Journal of Electric and Hybrid Vehicles, 2011, 3(03): 259-271.

[2] Qi Zhang, Surong Huang, Xuanming Ding, et al. Multi-domain simulation of hybrid excitation machine with isolated magnetic paths. Journal of Mechanical Engineering, 2010, 46(6): 8-15. (in Chinese)

[3] Xueyi Zhang, Qinjun Du, Shilun Ma, et al. Nd-Fe-B permanent magnet generator and voltage stabilizing control technology for vehicles. Advances in Mechanical Engineering, 2016, 8(9): 1-11.

[4] TKosaka, M B Sridharbabu, M Yamamoto, et al. Design studies on hybrid excitation motor for main spindle drive in machine tools. IEEE Transactions on Industrial Electronics, 2010, 57(11): 3807-3813. 
[5] Xueyi Zhang, Qinjun Du, Shilun Ma, et al. Magnetic flux analysis and performance test of permanent magnet and claw-pole electromagnetic hybrid excitation generator for electric vehicle range extender. International Journal of Electric \& Hybrid Vehicles, 2017, 9(3): 187-205.

[6] E Sulaiman, T Kosaka, N Matsuin. High power density design of 6-slot-8pole hybrid excitation flux switching machine for hybrid electric vehicles. IEEE Transactions on Magnetics, 2011, 47(10): 4453-4456.

[7] Guangdong Tian, Honghao Zhang, Yixiong Feng, et al. Green decoration materials selection under interior environment characteristics: A grey-correlation based hybrid MCDM method. Renewable and Sustainable Energy Reviews, 2018, (81): 682-692.

[8] Guangdong Tian, Mengchu Zhou, Peigen Li. Disassembly sequence Planning considering fuzzy component quality and varying operational cost. IEEE Transactions on Automation Science and Engineering, 2017, (99): 1-13.

[9] D Fodorean, A Djerdir, I A Viorel, et al. A double excited synchronous machine for direct drive application-Design and prototype tests. IEEE Transactions on Energy Conversion, 2007, 3(22): 656-665.

[10] F Leonardi, T Matsuo, Y Li, et al. Design considerations and test results for a doubly salient PM motor with flux control. 199631 th IAS Annual Meeting Conference, San Diego, CA, USA: IEEE, 1996: 458-463.

[11] E Hoang, M Lecrivain, M Gabs. A new structure of a switching flux synchronous poly phased machine with hybrid excitation. 2007 European Conference on Power Electronics and Applications, Aalborg, Denmark: IEEE, 2007: 1-8.

[12] B Gaussens, E Hoang, M Lecrivain, et al. A hybrid-excited flux-switching machines for high-speed DC-alternator applications. IEEE Transactions on Industrial Electronics, 2014, 61(06): 2976-2989.

[13] Zongsheng Zhang, Xiuhe Wang, Yubo Yang. A variable structure magnetic circuit model of novel hybrid excitation flux switching motors. Proceedings of the CSEE, 2014, 34(21): 3467-3474. (in Chinese)

[14] Yu Wang, Zhiquan Deng. Comparison of hybrid excitation topologies for flux-switching machines. IEEE Transactions on Magnetics, 2012, 48(9): 2518-2527.

[15] Wei Hua, Gan Zhang, Ming Cheng, et al. Electromagnetic performance analysis of hybrid-excited flux-switching machines by a nonlinear magnetic network model. IEEE Transactions on Magnetics, 2011, 47(10): 3216-3219.

[16] Qunjing Wang, Guoli Li, Fei Ma, et al. Investigation and calculations on 3-dimensional field and inductance of a hybrid claw-pole alternator with
PM excitation. Transactions of China Electrotechnical Society, 2002, 17(5): 1-5. (in Chinese)

[17] Qunjing Wang, Jun Chen, Weidong Jiang, et al. The modeling and calculating on a new type hybrid claw-pole alternator. Proceedings of the CSEE, 2003, 23(2): 67-76. (in Chinese)

[18] Surong Huang, Qi Zhang, Guodong Xie, et al. Hybrid excitation machine with bypass flux path. China, 200510112090.4, 2005-12-28. (in Chinese)

[19] Xueyi Zhang. The research on the technology of permanent magnet and electromagnetic hybrid excitation power generation system recycle vehicle exhaust surplus energy. Shandong University of Science and Technology, 2011: 74-84. (in Chinese)

[20] S H Lee, S O Kwon, J J Lee, et al. Characteristic analysis of claw-pole machine using improved equivalent magnetic circuit. IEEE Transactions on Magnetics, 2009, 45(10): 4570-4573.

[21] Shigui Zhou, Haitao Yu, Minqiang Hu, et al. Nonlinear equivalent magnetic circuit analysis for linear flux-switching permanent magnet machines. IEEE Transactions on Magnetics, 2012, 48(48): 883-886.

[22] Yichang Wu, Bo-Syuan Jian. Magnetic field analysis of a coaxial magnetic gear mechanism by two-dimensional equivalent magnetic circuit network method and finite-element method. Applied Mathematical Modelling, 2014, 39(19): 5746-5758.

[23] K Boughrara, R Ibtiouen, D Zarko, et al. Magnetic field analysis of external rotor permanent-magnet synchronous motors using conformal mapping. IEEE Transactions on Magnetics, 2010, 46(9): 3684-3693.

[24] Ping Jin, Shuhua Fang, Heyun Lin, et al. Analytical magnetic field analysis and prediction of cogging force and torque of a linear and rotary permanent magnet actuator. IEEE Transactions on Magnetics, 2011, 47(10): 3004-3007.

[25] Xueyi Zhang, Liwei Shi. Stabilivolt analysis of 42V Nd-Fe-B permanent magnet generator for automotive. Automotive Engineering, 2011, 33(11): 994-997.

[26] S Moimoto. Trend of permanent magnet synchronous machines. IEEJ Transactions on Electrical and Electronic Engineering, 2007, 2(2): 101-108.

[27] G Bai, R W Gao, Y Sun, et al. Study of high- coercivity sintered Nd-FeB magnets. Journal of Magnetism and Magnetic Materials, 2007, 308(1): 20-23.

\section{Submit your manuscript to a SpringerOpen ${ }^{\odot}$ journal and benefit from:}

- Convenient online submission

- Rigorous peer review

- Open access: articles freely available online

- High visibility within the field

- Retaining the copyright to your article

Submit your next manuscript at springeropen.com 